\title{
Valuing Culture \\ IN THE GLOBAL CitY ${ }^{1}$
}

\author{
John Holden \\ City University, London - Demos
}

ABSTRACT: Culture encompasses three highly inter-related spheres of publicly funded culture, commercial culture and home-made culture. Cultural policy-making therefore needs to address many issues beyond traditional concerns.

KEYWORDS: culture, creative industries, cities, cultural value.

RESUM: La cultura presenta tres formes estretament interrelacionades: la cultura amb finançament públic, la cultura comercial i la cultura casolana. Per tant, les polítiques culturals han de tractar molts aspectes a banda dels tradicionals.

Paraules Clau: cultura, indústries creatives, ciutats, valor cultural.

RESUMEN: La cultura engloba tres ámbitos estrechamente interrelacionados: la cultura con financiación pública, la cultura comercial y la cultura hecha en casa. Por lo tanto, las políticas culturales deben tratar muchos aspectos más allá de los tradicionales.

Palabras clave: cultura, industrias creativas, ciudades, valor cultural.

1. This is an edited version of a speech given at a University of Chicago conference on The Future of the City, which took place at the Chicago Cultural Centre on June 7th 2011. 
$\mathrm{I}$

was delighted to be asked to come here to talk about the issue of valuing culture in the global city, because I think it's a really interesting question.

Why do I say that? Well, partly because the world is getting increasingly citified, so what happens in cities matters to more and more of us. In 2008, for the first time in history, the proportion of the global population living in cities passed $51 \%$. China has gone from having $18 \%$ of its population living in cities in 1978 to $50 \%$ today, and here in the us, $80 \%$ of people live in cities. Even if you don't live in a city, you are still likely to get your news, entertainment and quite possibly your value system from cities. The trend shows no sign of stopping, so it looks as if our future will increasingly be an urban one.

The second reason why I think it's interesting is because I find the role of culture in the life of cities something of a conundrum. I look at the lists of the world's most liveable cities, as they appear in magazines like Monocle, and I'm struck by the fact that most aren't places that I'd want to be, even when they have some lovely cultural infrastructure. I mean, Fukuoka at number 14 ? Portland at number 21? and neither New York or London making the grade? Come on! On top of that, some places that are very rich in the culture of the past, like Kyoto or Florence might be very nice, but they just don't cut it as pumping, happening, global cities.

Then you've got the fact that the financial districts of even the world's most prosperous cities are as dull as ditchwater - just look at Wall Street and the City of London - utterly awful.

So for me successful cities are places that are culturally and financially active, right here and right now: they combine the making of money with the making of meaning. These are cities that people actually want to move to; places where history and news are made, and where living artists thrive. Places that get drawn and painted, and built and written about in real time. Often these are places that surprise and confound and are not entirely comfortable, and if you want me to name names, then I'd put Berlin and Istanbul high on my list.

I also find it interesting that in the West the role of the traditional arts in the life of cities seems to be changing. In the nineteenth and twentieth centuries, any city with ambition wanted to host a world class museum, an 
orchestra, and maybe an opera house (for example there are opera houses in the gold-rush town Central City, Colorado and in Manaus in Brazil).

But today, by contrast, some of those traditional arts institutions are in crisis in American cities, and they are under threat in parts of Europe. And the reason for that is because the importance of the arts is no longer an unquestioned given. Politicians and private philanthropists everywhere are asking some difficult questions - what value do the arts and culture provide to the place where I live? Does it matter if the traditional arts disappear?

And there are equally important questions that city politicians must ask of themselves - how should they react to the changes that are going on in arts funding patterns; what responsibilities do they have in relation to culture? How do they optimize the regulatory and fiscal tools at their disposal?

Now, answering these questions is made more difficult than it otherwise would be, because we are collectively in a muddle about some of the important terms in the debate, especially the words 'culture' and 'value'. We no longer have a shared understanding about what they mean. And we are also troubled by the metrics of culture: how do we measure and compare across the arts landscape and beyond?

So that's the starting point for my talk today. I will attempt to provide a simple conceptual framework that will help us to talk about the role of the arts and culture in the city. After that I will argue that a city without the arts is doomed to economic, social, and political failure. And then I will suggest some approaches that cities should take when it comes to culture.

So, let's start with the Cambridge academic Raymond Williams. In 1976 he wrote that culture was one of 'the two or three most difficult words in the English language'. Back then culture essentially had two different meanings - and most people still think about culture in this way.

On the one hand culture meant 'the arts' - and the arts were an established canon of art forms (opera, ballet, poetry, etc.), each of which contained its own hierarchies. Now the arts were enjoyed by only a small part of society; one that was also generally speaking well educated and rich, and this social elite defined itself not just through money and education, but through the very act of appreciating the arts, and that's why the arts themselves came to be labelled as elitist. 
So that was one meaning of culture, but there was another one; a more anthropological meaning that extended to include everything that we did to express and understand ourselves as individuals within a group; from cooking to sports to dancing to watching television.

The problem was, and still is, that these two meanings of the same word became oppositional. Culture in the sense of the arts, and popular culture were mutually exclusive: one was high, the other was low, one refined, the other debased. As an individual, you could aspire to high culture, but by definition, high culture could never be adopted by everyone - that was a logical impossibility, if everyone adopted it, it would be popular culture. And to invert the logic, if under this old model popular culture was popular, that meant the arts must be unpopular. Oh dear.

But don't despair, because this old either/or model of culture, that a lot of people still cling to, is redundant. The meaning of culture has to be radically rethought because two things have happened. The first is an obvious one: and that is that the old notion that somehow particular forms of culture are inherently better than others - by which I mean that they are more capable of bearing intense meaning - that idea has been untenable for quite some time. In fact it became crystal clear in the 1960s that the best cultural responses to the Vietnam war came not from the opera house or from literature; instead they came from journalism, film and rock music, and the high point was when Jimi Hendrix played the Star Spangled Banner at Woodstock.

So the question is no longer, 'is theatre better than TV drama?' or 'is ballet better than streetdance?'. Instead the debate about cultural quality moves to niches: is that a good Othello? is that a great TV programme? how do these jazz musicians rate? and so on.

That's the first reason why we have to rethink the relationship between the arts and the rest of culture. The second imperative for a rethink flows from a much more recent, and much more fundamental, shift in the way that the cultural system works.

Let me explain what I mean. My contention is that now, for practical purposes, we no longer have the arts and the rest of culture. Instead, there are three, deeply interrelated, spheres of culture: funded culture, commercial culture 
and home-made culture. Unlike the old high art and popular art they are not separate or oppositional; instead they are completely intertwined. However, they are different from each other in important ways.

Funded culture is the type of culture that needs support from governments or philanthropists. This type of culture is defined not through theory but by practice: what gets funded becomes culture. Therefore, who makes these decisions about what to fund, how those decisions are made, and hence who gets to define this type of culture, is a matter of considerable public interest. Who gets funded to do what, and how a society decides to allocate the power to make funding decisions - whether these decisions should be taken in the boardrooms of corporations, or by national or city politicians who are accountable though the ballot box, or by arm's-length expert agencies - all of these are intensely political questions.

The next type of culture, commercial culture, is equally pragmatically defined: the consumer is the ultimate arbiter and if someone thinks there is a chance that a song or a show will sell, it gets produced. Success or failure is market driven, but crucially access to the market - the elusive 'big bucks record deal' that Bruce Springsteen sings about in his song Rosalita, or the stage debut, or the first novel - those are controlled by a corporate elite who are just as powerful as the arbiters of funded culture. The really important thing here is that both in funded culture and in commercial culture there are gatekeepers who define the meaning of culture through their decisions. In both cases, if you are an artist you have to overcome an obstacle in order to get your work in front of an audience.

But in the third sphere of culture - home-made culture - that is no longer the case. Home-made culture extends from the historic objects and activities of folk art, through to the post-modern punk garage band and the YouTube upload, and here, the definition of what counts as culture is much broader; it is defined by an informal self-selecting peer group, and the barriers to entry are much lower. Knitting a sweater, singing in a choir, or writing a song and posting it on Facebook might take a lot of skill, but they can be done independently without much difficulty - the decision about the quality of what is produced then lies not in the hands of an expert, but in the hands of those who see, hear or taste the finished article. 
In the past thirty years we have seen an explosion of activity in this third space of home-made culture. Let me ask you: what proportion of the twenty-year olds that you know are in a band, or curate their photographs, or make films with their camcorders? A hundred percent, right? Everyone under the age of 25 seems to be an aspirant musician, poet, writer or filmmaker. In part that's because the means of production have become cheaper and easier to use. You can now make a film on a $\$ 200$ camera and edit it on a laptop, instead of needing a crew of 50 unionised workers and a capital-intensive studio.

But the really revolutionary technological innovation has been the internet. What the internet has done - uniquely and irrevocably, and in an incredibly short space of time - is to enable people to use culture to communicate, collaborate, and make money in ways that are entirely new.

This has played havoc with the business models of the music, film and broadcasting sectors. And it has changed the possibilities for all three spheres of culture and all forms of cultural expression within them, presenting a wealth of new opportunities (such as new audiences; new art forms; new distribution channels) but also a set of questions (what to do about intellectual property; what to fund; how to educate young people; and censorship for example).

By fundamentally changing the rules of the game, this revolutionary technology has also changed the role of culture in people's lives. Instead of being passive consumers of culture, dumb audience members sitting in the dark in silence, nowadays we all take on positions as producers and consumers, authors and readers, performers and spectators all of the time. We graze in comfort across these three spheres of culture without a second thought. Each of us moves fluidly through our cultural lives, creating our sense of individual and collective identity as we go; and we increasingly define ourselves by what we choose to watch, read, listen to and so on.

And just as this integrated model of culture explains how and why the arts and culture together have become more important for individual people, by extension it explains why this big cultural landscape has become more important to cities and why culture will, I think, become more and more important in the world of politics and policy. 
Because under the old model of culture, the high arts could be dismissed as a narrow elitist pursuit; commercial culture could be written off as populist entertainment; and home-made culture could be patronized as 'amateur'. But put all three together into one completely interlinked and interwoven activity, and culture transforms into being what Jordi Marti, the former Head of Culture in Barcelona, calls 'the second ecosystem of humankind.'

Now, if all that sounds too high-falutin and theoretical, let me present you with some of the reality of how culture now affects the life of cities and nations.

First, this broad sweep of interconnected cultures has become economically important. In a publication I wrote a few years ago, with the admittedly uninspiring title of Publicly Funded Culture and the Creative Industries, I looked at the ways in which the funded arts and the money-making cultural industries were inseparable - because of the way that ideas and skills are shared, because of the way that one creates a market for the other, and because of the way that people make a living by operating right across this cultural landscape.

A couple of examples: the famous British actor Sir Ian McKellan appeared in Lord of the Rings, but was classically trained at the Royal Shakespeare Company; and the TV advert for a brand of bread called Hovis has a backing track that uses Dvorak's New World Symphony played, I believe, by the publicly funded Halle Orchestra. And on and on these connections go. My point here is that so-called high arts are not divorced from the economy of the rest of the creative industries: they are an absolutely essential driver of those industries.

And together they form a significant sector of the economy - where I come from in the UK the creative economy accounts for between $7 \%$ and $11 \%$ of GDP, depending on what's included. That's a lot of money and a lot of jobs. In most OECD countries this is one of very few parts of the economy that is significantly outperforming the rest. But rather than thinking of it as an economic sector, I think we should be thinking of the creative economy as an economic system, and like all systems, it needs all of its parts in order to function. 
A second area of economic growth is in cultural-led tourism, which is why you see cities from Abu Dhabi to Oporto and from Hong Kong to Sydney investing heavily in new cultural buildings. And then there is urban regeneration, where culture has refreshed parts of cities and led to huge increases in property values.

Suffice to say that cities all around the world have realised the importance not only of the creative economy itself, and the jobs it creates, but also the knock-on effects of cultural activity as an attractor of a highly educated workforce for other sectors.

In many cities, smart public sector investment is driving private sector prosperity, just as it has always done. But here is an important point. We are all familiar with the idea that physical infrastructure such as roads and waterpipes are an essential component of building a city. We can, by extension, get our heads around the need for physical cultural infrastructure like museums and concert halls. What is less familiar, but now equally important, is the idea of investing in the less visible infrastructure of connectivity.

The Harvard economist Edward Glaeser says in his book, Triumph of the City, that what thriving cities do is "attract brilliant people and then connect them". It is interconnection that nurtures and develops human capital. Cities need to constantly form new connections in order to regenerate and renew themselves. They need stimulus and diversity. This is why port cities, like Venice and San Francisco, have historically succeeded whereas single-industry towns that have lost their connectivity, like Detroit and Liverpool, have failed.

And this is another reason why cultural life is so important, because not only does the cultural world provide essential social spaces where interconnection takes place; it's also the case that what happens in those spaces creates the norms of behaviour that build social capital. In turn social capital underpins the relationships and transactions that make a city and its economy function and thrive.

What then are the implications of all this for cities? Well first, I think we need a shift in mind-set away from city governments thinking of themselves as providing or delivering culture. I have explained how the entry-costs to 
self-expression have been lowered and that we now have an observable phenomenon of mass engagement with all sorts of different types of culture. The job of city governance is to enable people to be part of that - to increase their opportunities for enjoying themselves, to improve their ability to learn from the cultures of the past and the present, and to give them the tools and the confidence to create the culture of the present and the future.

This involves not just providing the built infrastructure of culture - the symphony halls, the theatres and the galleries, the bars that host live music, and the cinemas - but paying attention to the capacity of people to use those places. In turn that means looking at such things as the education system; how the transport network and planning decisions support cultural activity; it means taking an interest in how cultural organizations treat both citizens and visitors.

In other words, it's a lot more complex and wide-ranging than it used to be - but also potentially much more rewarding. Get this right and the city will flourish socially and economically; get it wrong and the city will fail.

Now, I want to spend a little time talking about how we might articulate and measure some of what I have been talking about. If culture is so important, how can we get a handle on the value of culture in cities?

Before I do that, let me just recap where we've got to:

What I've been arguing is first, that we need to reframe the arts as an essential part of a broader concept of culture; second, that cultural life has been transformed over a very short space of time from something that was marginal, into something that has become hugely important for our personal and community identity, as well as being of significant and growing importance economically. Third, I have maintained that a successful global city needs to understand these trends and changes, and then needs to construct the physical, regulatory and fiscal environments that will nurture a rich cultural life for its citizens. That in turn means paying attention to things that used to be considered outside the consideration of cultural decisions. Finally I've said that I think cities neglect the arts and culture at their peril; and the price of failure is high not just economically but also in terms of human development and fulfilment. 
But I understand that in political and policy terms, the arts and culture are very difficult to deal with: they often seem to be simultaneously soft, fluffy and slippery.

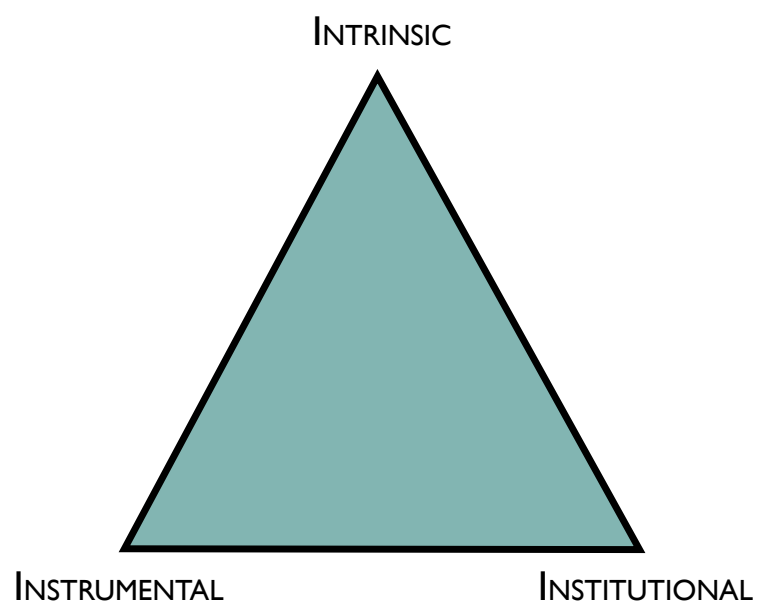

I have in the past put forward this simple diagram to try to articulate the different values that culture can have to different groups in society. Put briefly, the argument is this: that you can look at the value of culture in three ways, using different sorts of language in each case. These three viewpoints are not mutually exclusive; on the contrary they are complementary, but depending on who you are, they are more, or less, important.

Let me explain. At the top of the triangle is Intrinsic value. Intrinsic means integral to, or an essential part of. So this implies that museums, dance, theatre and so on, have a value in themselves. Each of them provides a unique way of communicating that would be lost if they didn't exist, and that fact alone establishes the arts as a public good in their own right: we should value dance because it is dance and poetry because it is poetry, and not just because dance and poetry have economic and social impacts.

But the term intrinsic value is also used to describe the way that art forms have individual, subjective effects on each of us. Intrinsic value is what people are talking about when they say "I love to dance" or "that painting's rubbish" or "I need to write poems to express myself". 
Now, intrinsic value is notoriously difficult to describe, let alone measure, and the rational econometrics of government simply can't cope with it, because this aspect of culture deals in abstract concepts like fun, beauty and the sublime. It affects our emotions individually and differently, and it involves making judgments about quality. It really doesn't fit with the hard-headed machismo that is supposed to dominate in business, politics, sport and the media. These days, if you can't count it, it doesn't count.

But to me, or to you, as an individual, it is our own subjective response to culture that really matters. When I sit in a darkened auditorium listening to, say, Mozart's Requiem, my feelings are awakened and I think "this is lovely, it's amazing, it's astonishing". I don't sit there thinking, 'I'm so glad this performance is driving business prosperity and helping to meet tourism targets in the greater Chicago area".

So if we are talking about the value of culture to individuals, we need to talk about quality, excellence, physical and intellectual access, and audience demographics. We need to take qualitative factors into account - to argue about what is good and bad art, what excellence consists of, and how audience experiences can be improved. We can only have those debates through narrative and language and debate; numbers can provide a proxy for some of it, but can never give us the full picture.

It's important to realize that when we are talking about intrinsic value, we are using value as an active verb. I value something, you value something, they value something. And that process of valuation is subjective. You can tell me that a painting is good and try to explain why you think so. You can give me the statistics that show that dancing will benefit me in all sorts of ways from making me healthier to making me happier. But only I can value the painting, or the dance. This, I think is a crucial point.

Because when we turn to the second type of value, instrumental value, we are dealing with an objective concept, so here we have to think about value differently. Instrumental value is used to describe instances where culture is used as a tool or instrument to accomplish some other aim - such as economic regeneration, or improved exam results, or better patient recovery times. These are the knock-on effects of culture, looking to achieve things that could 
be achieved in other ways as well. This type of value has been of tremendous interest to funders over the last thirty years or so, and at some points it has become so overwhelmingly important that the other values of culture have been forgotten.

I think there are perfectly understandable reasons why that has been the case. One of them is that funders need to take decisions between competing demands on their money, so they want to find objective measures that quantify the effects of their investment. Instrumental values provide just those sorts of metrics; they take a start point and an end point and measure the change in between. They are, therefore, important, but they don't tell the whole story.

A full account of cultural value needs to talk about both the subjective individual experience of culture - in other words intrinsic value - and the objective, measurable benefits that culture produces - instrumental value. But there is something else that needs to be discussed as well, and I call this Institutional value.

This is all about the way that cultural organizations act. They are part of the public realm and so how they do things creates value as much as what they do. In their interactions with the public, cultural organizations are in a position to increase - or indeed decrease - such things as our trust in each other, our idea of whether we live in a fair and equitable society, our mutual conviviality and civility, and a whole host of other public goods. So the way in which our institutions go about their business is important. Things like opening hours, meeting and greeting, providing opportunities to grow and to learn are not simply about customer care as they would be in the commercial world. No, they are much more important than that, because they can act to strengthen our sense of nationhood and our attachment to our locality and community.

Institutional value exists as the social dimension of culture, and its social utility can take many forms: for example culture enables a range of democratic voices to be heard; particular cultural events can either challenge or support the status quo; either way, they provide an important democratic space through which our society develops. 
The question is, how to count institutional value? Well here, in contrast to instrumental value, where you are trying to find out the objective, measurable benefits of culture, here, what you want to know is the value that people collectively place on culture. And so you must ask them what they think, through surveys and focus groups and contingent valuation techniques.

But to sum up our value triangle, you can see these three ways in which culture can be valued: intrinsically, instrumentally, and institutionally. I want to stress that these are not three distinct categories where we put different experiences or art forms. It's not that contemporary dance is all about intrinsic values and theatre all about institutional values. My point is that all these three values are viewpoints or perspectives of equal validity, and they should be considered together. Seeing all three values as essential aspects of culture, or as equal viewpoints, avoids both the dangerous predominance of any one of them, and the dangerous reductivism inherent in looking at culture through only one academic discipline, whatever that may be.

Taken together, these three ways of valuing culture provide cities with a set of hard and soft, qualitative and quantitative methodologies to articulate the value of culture. And once that is in place, politicians, funders, and arts organizations have shared terms of reference to have a sensible debate about investment.

And that investment is not directed to providing a settled culture to the citizens of the city; rather it is directed towards enabling those citizens to live a full and rich cultural life where they understand both the cultures of the past, and the global cultures of the present, but where they can also create their own culture, today and tomorrow.

Let me finish by describing two pictures. They were painted in about 1339 on the walls of the Palazzo Pubblico in Siena by Lorenzetti and they show allegories of good and bad city government.

Bad government is typified by crumbling buildings, people fighting each other, and scarcity: there is smoke and famine. By contrast good government looks exactly like what I've been talking about: a prosperous place where singing and dancing are an important part of life. It's a beautiful vision, and as true today as it was 700 years ago - it is up to city governments to make that rich cultural life a reality for everyone. 


\section{References}

Christakis, N. and Fowler, J. (2009): Connected: The Amazing Power of Social Networks and How they Shape our Lives, Harper Press, London.

Glaeser, E. (2011): Triumph of the City, Penguin, New York.

Holden, J. (2006): Cultural Value and the Crisis of Legitimacy, Demos, London.

- (2008): Democratic Culture, Demos, London.

SEABrook, J. (2000): Nobrow: The Culture of Marketing and the Marketing of Culture, Methuen, London. 